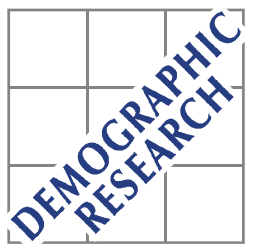

Demographic Research a free, expedited, online journal of peer-reviewed research and commentary in the population sciences published by the Max Planck Institute for Demographic Research Konrad-Zuse Str. 1, D-18057 Rostock · GERMANY www.demographic-research.org

DEMOGRAPHIC RESEARCH

VOLUME 12, ARTICLE 1, PAGES 1-28

PUBLISHED 23 FEBRUARY 2005

www.demographic-research.org/Volumes/Vol12/1

DOI: 10.4054/DemRes.2005.12.1

Research Article

\title{
The effect of education on the timing of marriage in Kenya
}

Lawrence D. E. Ikamari

(C) 2005 Max-Planck-Gesellschaft. 


\section{Table of Contents}

1 Introduction 2

1.1 The theoretical link between education and age at 3

first marriage

2 Source of data 7

3 Method of data analysis $\quad 7$

$4 \quad$ Results and discussion $\quad 11$

$\begin{array}{lll}4.1 & \text { Bivariate analysis } & 11\end{array}$

4.2 Multivariate analysis based on all women $\quad 11$

4.3 Multivariate analysis based on ever- married 18

women

5 Discussion $\quad 21$

6 Acknowledgements 23

References $\quad 24$ 


\title{
The effect of education on the timing of marriage in Kenya
}

\author{
Lawrence D. E. Ikamari ${ }^{1}$
}

\begin{abstract}
This paper investigates the effect of education on the timing of marriage among Kenyan women and the relative effects of education across generations of women. Data used is drawn from the 1998 Kenya Demographic and Health Survey. The Cox proportional hazard model and linear regression analysis are used to analyse the data. The results show that education has a statistically significant and strong positive effect on a woman's age at first marriage; the effect remaining robust in the presence of a number of controls. The highly educated women are more likely to delay marriage. Significant variations in the effect of education across the generations of women are apparent. The effect is greater for the younger women, indicating increased postponement of marriage. Premarital sexual activity, premarital childbearing, region of residence, religion and year of birth are also significantly associated with age at first marriage.
\end{abstract}

Population Studies and Research Institute, University of Nairobi, P. O. BOX 30197- 00100, Nairobi, Kenya. Fax \#254 02245566 E-mail: likamari@uonbi.ac.ke 


\section{Introduction}

Marriage is an important institution both for the individual and the society at large. For the individual, it is a significant and memorable event in one's life cycle of as well as the most important foundation in the family formation process. It is also a rite of passage that marks the beginning of an individual's separation from the parental unit, even if generations continue to be socially and economically interdependent. For the society as a whole, it unites several individuals from different families and represents the creation of a production and consumption unit as well as one for the exchange of goods and services (Quisumbing and Hallman, 2003).

In most societies marriage defines the onset of the socially acceptable time for childbearing and is the most predominant context for childbearing in most countries. Age at marriage is of particular interest because it marks the transition to adulthood in many societies; the point at which certain options in education, employment, and participation in society are foreclosed; and the beginning of regular exposure to the risks of pregnancy and childbearing. Women who marry early will have, on average; a longer period of exposure to the risk of pregnancy, often leading to higher completed fertility. Variation in age of entry into marriage helps explain differences in fertility across populations and also helps explain trends in fertility within individual populations over time (United Nations, 1990; Ezeh and Dodoo, 2001). Therefore, age at first marriage has a direct bearing on fertility behaviour (Davis and Blake, 1965; Coale, 1971; Lesthaeghe et al., 1989).

Early marriage is associated with early childbearing as, in most cases particularly in the developing world, the main purpose of marriage is to have children. Early childbearing is fraught with substantial health risks for both the mother and the child. Young mothers are more likely to experience pregnancy related complications and less able to deal with them, which often lead to maternal death (Zabin and Kiragu, 1998). Children born to young mothers are usually subject to elevated risks of morbidity and mortality (Casterline and Trussell, 1980; Zabin and Kiragu, 1998; Ikamari, 1996).

Delayed age at marriage directly affects completed fertility by reducing the number of years available for childbearing. Later marriage permits women to complete their education, build labor force skills, and develop career interests that compete with childbearing within marriage. These career interests may, in turn, motivate women to limit family size and / or widen the spacing of their children (Amin, 1995; Jensen and Thornton, 2003).

Given the centrality of marriage in an individual's life history and its role in fertility and mortality transitions, surprisingly few analytic studies have been undertaken on marriage patterns and its determinants in Kenya in the recent past. Studies elsewhere have, however, identified a number of factors that seem to influence 
marriage timing (Véronique, 2002; Singh and Samara, 1996; Jejeebhoy, 1995; Oppenheimer, 1988; Bloom and Trussell, 1984; Rindfuss and St. John, 1983). Increases in age at marriage are associated with major social-structural changes such as increases in educational attainment, urbanization, and the emergence of new roles for single women (United Nations, 1987, 1988; Lesthaeghe et al., 1989, Singh and Samara, 1996; Kaufman and Meekers, 1998). Jejeebhoy (1995) analyzed 51 studies based on a number of data sources, mostly the World Fertility Surveys and Demographic and Health Surveys (DHS), and found that education is the single factor most strongly related to the postponement of marriage, but the relationship may be subject to threshold effects. In many countries, the tendency for education to increase the age marriage becomes universal only after a few years of primary education. However, because the results of the few studies available are contradictory, little can be said about trends in the relationship between education and age at marriage over time (Jejeebhoy, 1995).

The nature of the association between education and timing of marriage has not been exhaustively investigated in Kenya particularly the relative effects of education across generations of women in the light of the increasing educational and career opportunities for young women (UNESCO, 2000). These changes have results in, among other things, increased participation of women in the modern economy and in salaried employment in the public sector that have profound implications for their traditional roles as mothers and wives. Given this scenario, it is possible the nature of association between education and marriage timing has also been changing over time in Kenya. Therefore this study primarily examines the relative effect of education on the woman's age at first marriage. In addition, the study aims at establishing the effects of some of the factors that have been indicated in studies elsewhere to be closely associated with the woman's age at first marriage. These include region and place of residence, childhood place of residence, age at first sexual intercourse, premarital childbearing and religion. The study uses the data drawn from the 1998 Kenya Demographic and Health Survey.

\subsection{The theoretical link between education and age at first marriage}

Education may affect the timing of marriage in various ways. The highly educated spend many years in school and college receiving instruction and knowledge. In Kenya today, one requires at least sixteen years to complete University education at the firstdegree level. When enrolled in school or college it is not desirable nor is it feasible for students to marry as it is disruptive and generally young people lack the financial resources and the prospect of a stable income that would be ideal for marriage and forming a family (Dixon, 1971; Oppenheimer, 1988; Goldscheider and Waite, 1991). 
Therefore school enrolment is an impediment to early marriage. Furthermore, there is usually strong social norm preventing person in school from marrying or even from forming co- residential partnerships (Blossfeld and Huinink, 1991; Blossfeld and Jaenichen, 1992; Thornton et al., 1995).

School attendance removes the girls from the domestic environment and offers literacy and exposure to new ideas and value systems that may compete with the traditional customs, values and beliefs that promote early marriage (Westoff, 1992, Caldwell et al., 1983). For example, Westoff (1992) has demonstrated with the data from the recent DHS from sub Saharan Africa that higher education delays marriage and postpones childbearing among women in the region. Estimates from the 1998 KDHS indicate that the median age at first marriage among the ever- married women aged 25-49 years with at least secondary education was 22 years compared with 17 years among those with no education (NCPD et al., 1999).

By exposing girls to non- traditional roles and providing them with the means to establish viable alternatives to early marriage, education expands the women's life opportunities and choices. Thus, the effect of education on the timing of marriage may relate to the development of value orientation and aspirations that give priority or preference to personal fulfilment and career development over traditional roles or early marriage and childbearing. Marriage is likely to be delayed or postponed when it is incompatible with the attainment of one's personal goals and ambitions (Bracher and Santow, 1998).

Education may also affect the age at first marriage through the use of effective contraceptive. Many studies show that educated women are more likely to use effective contraceptives than their uneducated counterparts. Education enables them to have access information on modern contraception and their proper use and to appreciate their role in fertility regulation. The use of effective contraceptives enables them to avoid unplanned pregnancy that may compel them to enter into marriage earlier than desired (NCPD et al., 1999).

Furthermore education may affect the timing of marriage through its influence on how the educated perceive themselves and how the society perceives them, and the perception about the value of children in a modern society (Caldwell et al, 1983). In the traditional society, women often relied on marriage and childbearing as avenues for gaining social status, respect and power in the household as well as in the community arena. Consequently, early marriage and childbearing were highly valued in many traditional societies (Caldwell and Caldwell, 1987). However, with the advent of education, women who are educated are respected and enjoy high social status, whether married or not, in the modern Kenyan society. In Kenya today, women's education is viewed as a crucial human capital investment and an avenue to salaried employment, independence, decision-making and enhanced social status. Thus the educated women 
no longer see marriage and childbearing as viable avenues to social status and economic independence.

Although education is the primary focus of this study we consider other potentially important explanatory variables. The inclusion of these other explanatory variables serves two main purposes, namely to facilitate the establishment of the net or relative effect of education, and to determine their respective effects on age at first marriage. These other explanatory variables are: region of residence, type of place of residence, religion and ethnicity. Elsewhere these factors have been found important in explaining variation in the timing of marriage (Smith and Karim, 1980; United Nations, 1990, Choe et al., 2004). For example, region of residence is indicated as the most important predictor of the pattern of age at marriage in Thailand and in Malaysia it is ethnicity (Palmore, 1983). Similarly, in Mozambigue, ethnicity is an important predictor of age at first marriage (Arnaldo, 2004).

Kenya is divided into provinces or regions namely, Nairobi, Central, Eastern, Coast, Eastern, North Eastern, Nyanza, Rift valley and Western. The country has significant socio-economic regional variations and the regions have been impacted differentially by modernisation. Generally due to historical and political reasons, Nairobi, Central and some parts of the Rift Valley province are more economically developed than the other provinces located at the periphery of the Capital City of Nairobi which is the seat of government. The regional socio-economic development disparities are bound to affect the timing of marriage. We would expect women residing in the more developed provinces to marry and start marry early later than their counterparts in the less developed provinces as the majority of them would be educated and have more opportunities for career development outside the home.

Furthermore, there are discernible regional cultural variations in Kenya, as one or two ethnic groups predominantly inhabit each of the eight regions. Central Province is predominantly inhabited by the Kikuyu, Coast Province by the Mijikenda, Nyanza by the Luo and Kisii, Western Province by the Luhya, Eastern by Kamba, Embu and Meru, Rift Valley by the Kalenjin, North Eastern by the Somali and Boran, while Nairobi Province is metropolitan. Each ethnic group has its own socio-cultural ideologies about reproduction. These ideologies are composed of the norms, beliefs and values as well as the practices that are likely to affect positively or negatively the reproductive performance of a given society. It is likely that each cultural group may stress certain aspects in their reproductive institutions. The group norms, ideals and beliefs have been used to explain ethnic variation in the timing of marriage and childbearing (Goldscheider, 1971; Addai and Trovato, 1999; Arnaldo, 2004). We would also expect significant variation in the age at first marriage across the regions of Kenya due to the cultural differences. 
Type of place of residence may be equally important, as rural areas generally are associated with early marriage. People living in urban areas are exposed to a more diverse life style and subject to a weaker social control than those in rural areas. Rural areas tend to have institutional and normative structures such as the kinship and extended family that promote early marriage and childbearing (Goode, 1963; Dixon, 1971; United Nations, 1988, 1990). These social structures and networks are less potent and individual responsibility in the matters of marriage is emphasized in urban areas. People in urban areas need to develop skills, gain resources and achieve maturity to manage an independent household and thus they have to delay marriage. Furthermore, urban women tend to be more educated and engaged in salaried employed than their rural counterparts. In Kenya, as in other developing countries, urban areas usually have the largest share of the country's well-educated, high income population and the best educational and health facilities (Ewbank et al, 1986). Thus, urban areas are expected to be associated with later entry into marriage.

Since the ecological, socio-economic and cultural environment of a woman's childhood place of residence or birth place influences her general health and well being and contributes to the formation of beliefs, aspirations and practices that are important during her adulthood, the type of childhood place of residence will also be included in analysis.

The study will also examine the effects of premarital sexual activity and childbearing (ex-nuptial births) and age at first sexual debut on age at first marriage. Pre-marital sexual activity and child bearing may prompt early marriage. Some studies elsewhere show that the presence and sometimes the number of ex-nuptial children reduce women's likelihood of marrying (Chiswick and Lehrer, 1990; Teachman and Heckert, 1985; Bennett et al., 1995). Year of birth will be included in the study in order to control for trend in the incidence of early marriages over time.

Finally, this study will also examine the effect of religion on the age at marriage. In Kenya, there are several religions and Kenyans are generally religious. The main denominations are Catholic, Protestant and Muslim. Religious norms and beliefs affect one's orientation towards marriage and childbearing, among other things; thus, religion is bound to affect a woman's age at first marriage.

We hypothesize that education has a significantly positive effect on the age at first marriage and that its effect has increased over time. We also hypothesize that the effect of education is largely independent of the age at first sexual debut, whether or not a woman had an ex-nuptial birth, region of residence, childhood place of residence, type of place of usual residence and religion. Furthermore, we hypothesize that younger generations of women are less likely to enter into early marriages compared to the older generations. 


\section{Source of data}

As indicated early the data for this study is drawn from the 1998 Kenya Demography and Health Survey (KDHS). The KDHS was conducted to collect data on fertility, family planning, maternal and child health, and information about HIV/AIDS. The survey was carried out as part of the worldwide DHS program. The survey covered a national representative sample of 7881 women aged 15-49 years; irrespective of their marital status i.e. both never married and ever-married women were covered. All the provinces except for North Eastern province were covered. This study is focusing on these 7881 women and the units of analysis are individual women. The sampling methodology as well an assessment of the quality of the data are presented and discussed extensively in the first country report of the Survey (NCPD et al., 1999).

\section{Method of data analysis}

The dependent variable is the age at first marriage measured in terms of completed years. During the survey all women were asked a series of questions regarding their marital status and whether they had ever lived with a man. All those who reported that they were ever married or ever-lived with a man, were asked to indicate how old they were at the time when they started, for the first time ever, living with a man as a wife, irrespective of the legality or otherwise of their union. The response to this question constitutes the woman's age at first marriage. All the women who indicated that they had never been in a union or lived with a man were considered single and as a result they were not asked the question about the age at first marriage. This is the standard way in which age at first marriage is being measured in the worldwide DHS program. It is worthwhile to note that in Kenya, non-marital cohabitation is hardly practiced and as such women who cohabit with men considered themselves as married.

The age at first marriage may be interpreted as survival time from a single state to married state. Throughout this interval, women may either enter into marriage or be right censored at the time of the survey. In this case, women who were single at the time of the survey constitute censored cases. Censored cases require special treatment in estimating exposure time, and as such, ordinary regression procedures are not appropriate (Allison, 1995). We, therefore use continuous time event history analysis techniques (Allison, 1984, 1995). In particular, the general proportional hazard (Cox) model is used to assess the effect of education and the other covariate on the timing of marriage. The model is generally described as: 


$$
h\left(t ; x_{1}, \ldots, x_{n}\right)=h_{0}(t) \cdot \exp \left(b_{1} \cdot x_{1}+\ldots .+b_{n} \cdot x_{n}\right)
$$

where $h(t,,$,$) denotes the resultant hazard, given the values of the n$ covariates for the respective case $\left(x_{1}, x_{2}, \ldots, x_{n}\right)$ and the respective survival time $(t)$. The term $h_{0}(t)$ is called the baseline hazard; it is the hazard for the respective individual when the values of all the covariates are equal to zero. The use of Cox regression in studying demographic processes such as the marriage is fairly common in the literature (Bracher and Santow, 1998; Choe et al., 2004; Arnaldo, 2004).

The use of the Cox model allows us not to specify the hazard function, the relationship between the hazard rate and the duration of risk exposure, which is often difficult to specify at the outset. The proportional hazard model assumes that the hazard function for an individual depends on the values of the covariates and the value of the baseline hazard. As a result, given two individuals, say two women, with particular values for the covariates, the ratio of the estimated hazards over time will be constant. In this study, this proportionality assumption was examined statistically by plotting $\log$ minus $\log$ (LML) on the survival time and it was not violated.

Hazard rate is the key concept of the proportional hazards model. Hazard rate measures the risk of making a transition from the absence of an event to the presence of an event, such as from being single to being married. Hazard rate is essentially a transition rate. The rate is measured by the ratio of number of cases experiencing the event at the end of a time interval to the total number of cases exposed to the risk of experience the event at the beginning of the time interval. In this study, a lower hazard rate implies a longer duration of waiting time for the event to occur, i.e. older ages at first marriage. In this paper, the coefficients of the covariates will be transformed by exponentiation and interpreted as risk ratios.

We present the results as risk ratios, which represent the relative likelihood of a woman with the specific characteristic of marrying in comparison to a woman who would be in the appropriate reference group. The risk ratio of the reference group or category is one (1.00). If the risk ratio of a given category is greater than 1.00 , this indicates greater risk of marrying, and when the risk ratio is less than 1.00, it indicates a lower risk of marrying compared to the reference group. In this analysis, a variable will be reported as having a significant effect, if its effect on the timing of marriage is statistically significant at least at the 5 per cent level of significance.

In an effort to further quantify the effects of education and other explanatory variables on the woman's age at first marriage, separate analyses are carried out among ever-married women. In these analyses linear regression analysis is used and the dependent variable is age at first marriage as reported by the ever-married women during the survey. 
In order to examine whether or not the effect of education on the timing of marriage changes over time, three different cohorts of all women based on their age at the time of the survey have been isolated as follows; under 30 years, 30-39 years and 40-49 years. The women who were aged 40-49 years in 1998 were born between 1948 and 1958, those aged 30-39 years were born between 1959 and 1968, and those aged under 30 were born after 1968. These cohorts are indicative of the cultural, socioeconomic and political factors that have generally shaped experiences of these women. Those aged 40-49 years were born during the pre-Independence period when Kenya was still under the British rule; those aged 30-39 years were born about, during and immediately after independence since Kenya gained Independence in 1963, while those aged less than 30 years were born 10-20 years after Independence.

The main independent variable in this study is the level of education of the woman as reported at the time of the survey and not at the time the women got married for the first time. However, since the level of education of women in Kenya does not radically change after marriage, we can assume that the level of education at the time of the survey is the same as the level of education at the time of the first marriage. This is measured in terms of no education, primary, and at least secondary education. All the other explanatory variables used in this study are nominal variables as specified in Table 1 that shows the percent distribution of the study population according to these explanatory variables. Due to lack of appropriate data, age at first sexual debut and whether or not a woman had an ex-nuptial birth are used to represent premarital sexual activity and childbearing. 
Table 1: $\quad$ Percent distribution of covariates: Kenya, 1998.

\begin{tabular}{|c|c|c|c|c|}
\hline \multirow{2}{*}{ Covariates } & \multirow{2}{*}{ Pooled sample } & \multicolumn{3}{|c|}{ Age at survey in years } \\
\hline & & $15-29$ & $30-39$ & $40-49$ \\
\hline \multicolumn{5}{|l|}{ Level of education } \\
\hline None & 12.8 & 5.0 & 16.8 & 37.9 \\
\hline Primary & 59.9 & 65.0 & 54.6 & 47.9 \\
\hline At least secondary & 27.2 & 30.0 & 28.6 & 14.2 \\
\hline \multicolumn{5}{|l|}{ Age at first sexual debut } \\
\hline No sex & 16.1 & 26.6 & 0.4 & 0.0 \\
\hline$\leq 15$ years & 35.5 & 30.5 & 41.2 & 46.0 \\
\hline $16-19$ years & 39.8 & 36.1 & 46.7 & 42.9 \\
\hline$\geq 20$ years & 8.7 & 6.8 & 11.7 & 11.1 \\
\hline \multicolumn{5}{|l|}{ Had an ex-nuptial birth } \\
\hline Yes & 16.9 & 15.8 & 20.3 & 15.7 \\
\hline No & 83.1 & 84.2 & 79.7 & 84.3 \\
\hline \multicolumn{5}{|l|}{ Childhood place residence } \\
\hline Urban & 15.7 & 16.6 & 15.8 & 11.6 \\
\hline Rural & 84.3 & 83.4 & 84.2 & 88.4 \\
\hline \multicolumn{5}{|l|}{ Type of place of residence } \\
\hline Urban & 22.4 & 23.3 & 23.4 & 17.3 \\
\hline Rural & 77.6 & 76.8 & 76.6 & 82.7 \\
\hline \multicolumn{5}{|l|}{ Region of residence } \\
\hline Nairobi & 5.3 & 5.9 & 4.9 & 3.8 \\
\hline Central & 10.0 & 9.7 & 10.6 & 10.0 \\
\hline Coast & 15.6 & 15.3 & 15.6 & 16.6 \\
\hline Eastern & 15.0 & 14.8 & 14.8 & 16.4 \\
\hline Nyanza & 17.6 & 17.8 & 17.2 & 17.8 \\
\hline Rift Valley & 25.1 & 25.1 & 26.5 & 22.7 \\
\hline Wester & 11.4 & 11.5 & 10.3 & 12.7 \\
\hline \multicolumn{5}{|l|}{ Religion } \\
\hline Catholic & 27.0 & 27.2 & 27.3 & 25.4 \\
\hline Protestant \& other Christian religions & 64.6 & 65.6 & 63.6 & 61.4 \\
\hline Other & 8.5 & 7.1 & 9.0 & 13.2 \\
\hline \multicolumn{5}{|l|}{ Year of birth } \\
\hline 1969-1978 & 60.12 & na & na & na \\
\hline 1959-1968 & 25.07 & na & na & na \\
\hline 1948-1958 & 14.80 & na & na & na \\
\hline Total sample (N) & 7881 & 4738 & 1976 & 1167 \\
\hline
\end{tabular}

Source: Primary Analysis of the 1998 KDHS data. na stands for not applicable. 


\section{Results and discussion}

\subsection{Bivariate analysis}

Analysis using descriptive statistics revealed that the median age at first marriage among the ever-married women was 18 years and substantial differences in the median age at first marriage by the level of education were clearly apparent. The median age at first marriage among women with no education was 16 years, 18 years for those with primary education and 20 years for those with at least secondary education.

In Figure 1, we further explored the association using the cumulative proportions of women experiencing the first marriage at specified ages. Except after exact age 27 years, there is ample evidence that the cumulative proportion attaining the first marriage was highest among women with no education, then followed by that for women with primary education and finally by that for women with at least secondary education. For instance, at the exact age 18 years, 71 percent of women with no education were already married compared to only 27 percent among those with at least secondary education. By the age of 20 years, 84 percent of the women with no education had already had their first marriage compared to 53 percent among those with at least secondary education. A similar pattern is apparent among all the women in all the three cohorts as depicted in Figures 2 to 4 . These results indicate more education leads to delayed entry into first marriage.

\subsection{Multivariate analysis based on all women}

The results obtained by fitting the Cox models using the pooled sample are presented in Table 2. Model 1 shows the results obtained when education was the only explanatory variable while Model 2 includes the other explanatory variables as well. As indicated by the $\log$ likelihood and the associated chi-squares, the two models are statistically significant. Education has a statistically significant effect on the timing of marriage; more educated women are less likely to marry early. The results in Model 1 indicate that the risk of first marriage was 56 percent lower for women with primary education compared with those with no education. The risk was 69 per cent lower for women with at least secondary education.

In the full model (Model 2) there is a slight reduction in the effect of education on the age at first marriage. The risk of first marriage was 24 percent, instead of 56 percent, lower for the women with primary education, while the risk for the women with at least secondary education was reduced to 46 percent from 69 percent. This 
Figure 1: Survival plot of age at first marriage: Kenya, 1998 KDHS

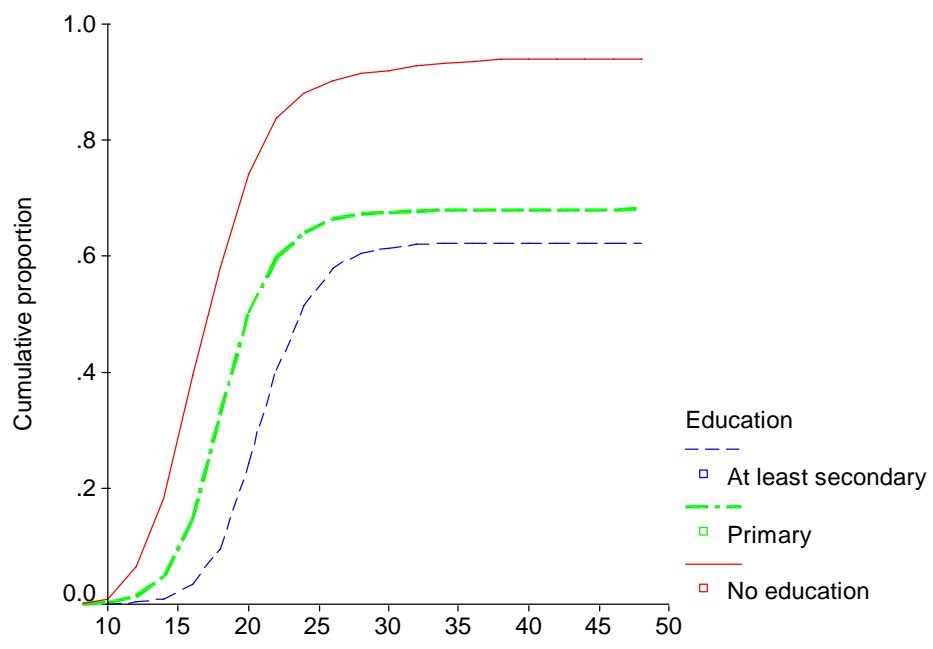

Age at first marriage

\section{Figure 2: Survival plot of age at first marriage: 15-29 cohort}

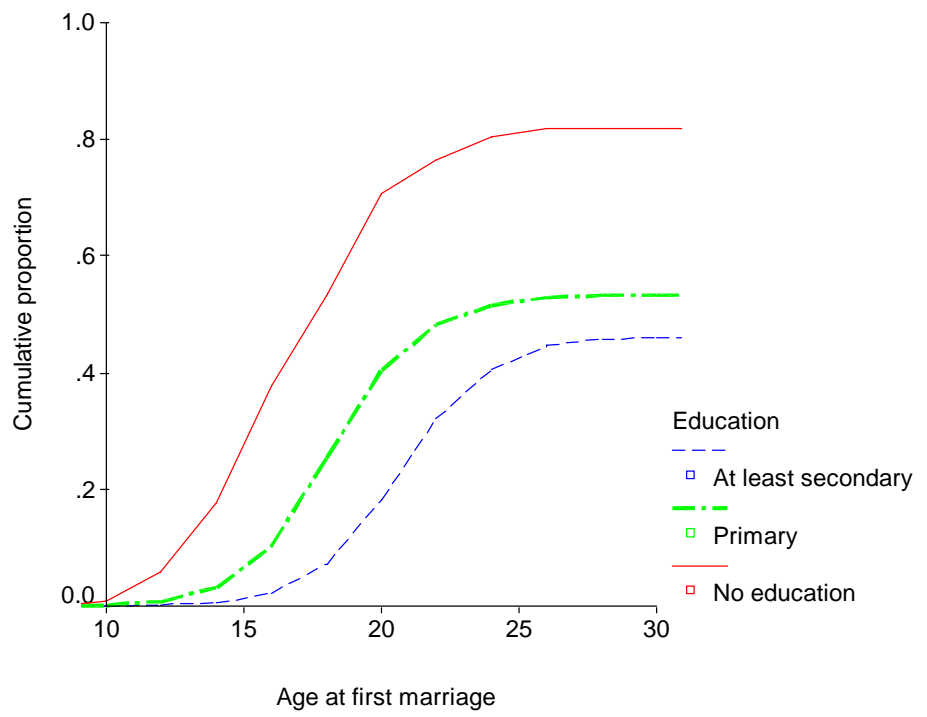


Figure 3: Survival plot of age at first marriage: 30-39 cohort

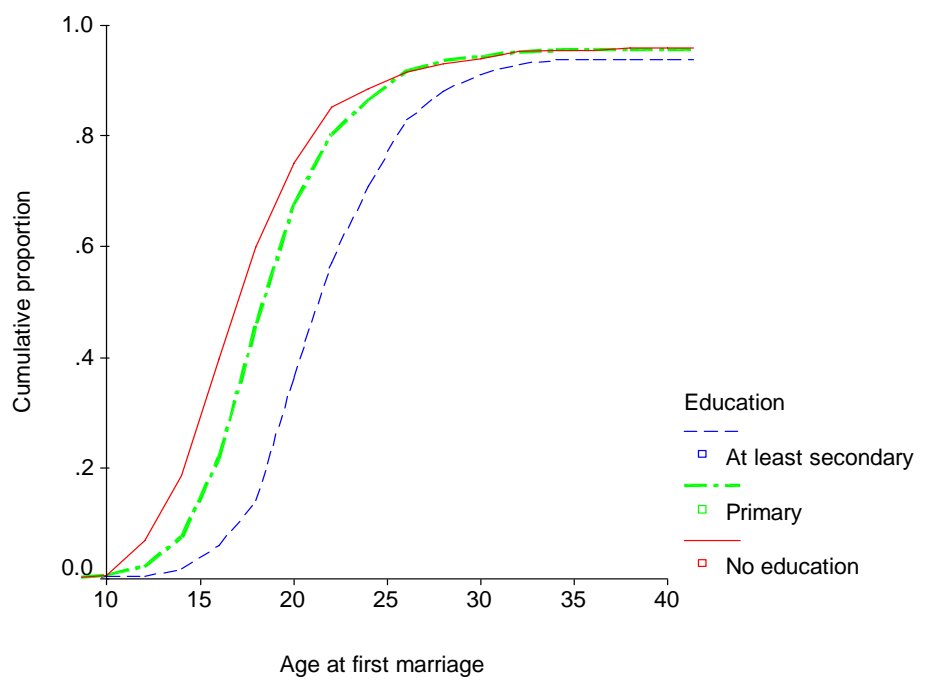

Figure 4: Survival plot of age at first marriage: $40-49$ cohort

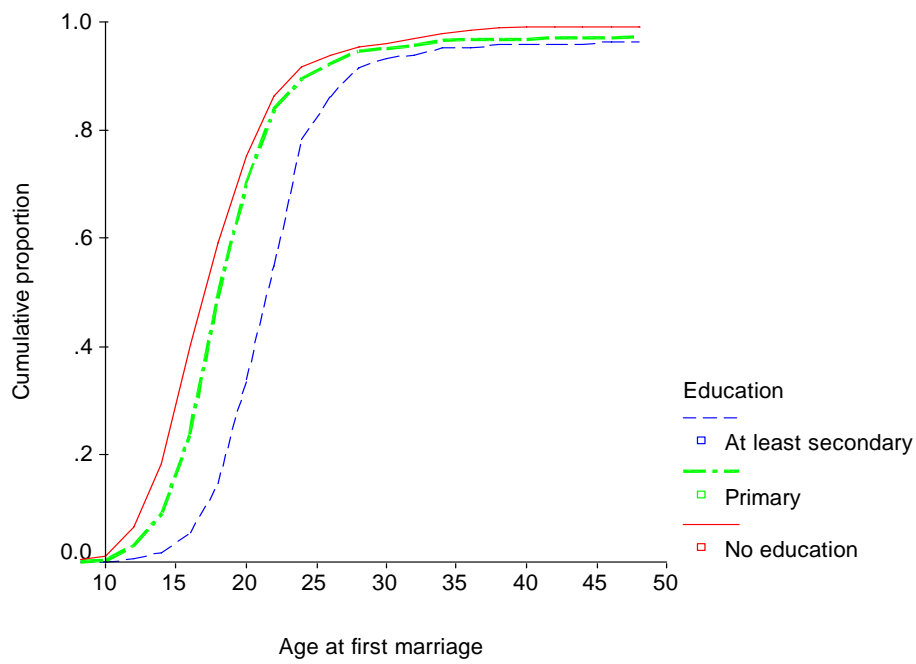


indicates that the effect of education is robust and largely independently of the type of place of residence, age at first sexual debut, whether or not a woman had an ex-nuptial birth, childhood place of residence, type of place of usual residence, region of residence and religion. This implies that these explanatory variables taken together can partially explain the effect of education on the age at first marriage.

The effects of age at first sexual debut, whether or not a woman had an ex-nuptial birth, type of place of usual residence, region of residence, religion and year of birth are also statistically significant. However, the effect of type of childhood place of residence is not statistically significant. This means that a woman's childhood place of residence is not important in determining the woman's age at first marriage in Kenya.

An early of age at first sexual debut is depicted as enhancing the pace of marriage. Women who initiate sexual activity before the age of 20 years are significantly more likely to enter in marriage early than those who start sexual activity when they are at least 20 years old. And women who have no sexual experience are significantly less likely to marry early compared to those who are sexually experienced.

Premarital childbearing has a significant effect on the timing of marriage. Having an ex-nuptial birth is associated with a lower risk of marriage. The risk of first marriage is 50 per cent lower for women with an ex-nuptial birth compared those with no exnuptial birth. This implies that having an ex-nuptial birth reduces that likelihood of entering into a first marriage by 50 percent. In Kenya, it is not culturally and socially acceptable for a young man to marry, as a first wife, a woman who already has a child. As result, prospective suitors generally avoid women with ex-nuptial births. Women with ex-nuptial births tend to very cautious in forming relationships with men as they generally distrust men.

With regard to the region of residence, the risk of first marriage was 49 percent higher for the women in Coast province, 40 per cent higher for women in Nyanza province and 32 per cent higher for women in Western province, 16 percent higher for women in Rift Valley province, all compared to women in Nairobi province. Compared with the women in Nairobi province, the risk of first marriage was not statistically different for women in the other provinces. Rural residence is associated with a slightly higher risk of first marriage; rural women are 1.13 times as likely as urban women to enter into a first marriage.

As evident in Table 2 religion has no significant net effect on the risk of first marriage. This therefore means that religion is not an important determinant of the timing of first marriage in the country.

As hypothesised, the year of birth is significantly associated with early marriage. Women born in the older generations were more likely to marry early compared to those born more recently indicating the likelihood of entering a marriage early is declining. For example, women born between 1948 and 1958 were 1.77 times as likely 
as those born between 1969 and 1978 to marry early. These results indicate a downward trend in the occurrence of early marriages in Kenya.

Table 3 presents the results of the analysis on each of the cohorts of women. In all the three cohorts, higher levels of education are associated with a lower probability of early marriage. . However, the effect is substantially greater for the younger cohorts. In the full model (Model 2), at least secondary education reduces the risk of marriage by 67 percent, 40 percent, and 30 percent for the 15-29, 30-39 and 40-49 cohorts, respectively. Among the younger cohorts primary education also significantly reduces the risk of marriage while in the older cohort its impact is substantially reduced. It reduces the risk of marriage by 52 percent, 17 percent and 12 percent (not significant) for the 15-29, 30-39 and 40-49 cohorts, respectively. The stronger effect of education among the younger cohorts of women could be due to enhanced career opportunities for educated young women and to continued weakening of traditions, normative systems and cultural practices that in past encouraged early marriages.

Age at first sexual debut is significantly associated with the timing of marriage in all the three cohorts. In each cohort, the risks of first marriage for women who initiated sexual activity early are substantially and statistically higher compared to women who initiated sexual activity when they were at least 20 years old. And women who are virgins are less likely to marry early compared to women who initiated sexual activity when they are at least 20 years old. The effect of the age at first sexual debut is stronger among the older cohorts than the young. This implies that in the past the onset of sexual activity was more likely to be soon followed by a marriage and than is the case among the younger cohort.

Whether or not a woman has an ex-nuptial birth is significantly associated with the risk of first marriage among women in all the three cohorts. The effect is greater for the younger cohorts than the older cohorts than. Having an ex-nuptial birth lowers the risk of marriage by 59 per cent, 46 per cent and 43 per cent for the 15-29, 30-39 and 40-49 cohorts, respectively.

Childhood place of residence has a significant effect only for women in the 15-29 and 40-49 cohorts. In these two cohorts women who grew up in rural areas had a slightly higher risk of first marriage compared to those who grew up in urban areas. Usual place of residence had a significant effect only for the 30-39-age cohort. In this cohort, rural women had a higher risk of first marriage compared to urban women.

Region of residence and religion have significant effects in all the three cohorts of women. In all the three cohorts, women in Coast, Nyanza and Western province are more likely to marry early compared to women in Nairobi province. For example, in the 40-49-age cohort, women in Western province are 2.19 times as likely to marry as their counterparts in Nairobi province. With regard to women in Rift Valley, it is only for 
Ikamari: The effect of education on the timing of marriage in Kenya

Table 2: $\quad$ Hazard models of the risk of first marriage (pooled sample): Kenya, 1998

\begin{tabular}{|c|c|c|}
\hline Covariates & Model 1 & Model 2 \\
\hline \multicolumn{3}{|l|}{ Level of education } \\
\hline None & 1.00 & 1.00 \\
\hline Primary & $0.44^{\star * *}$ & $0.76^{\star * *}$ \\
\hline At least secondary & $0.31^{\star \star *}$ & $0.54^{* * *}$ \\
\hline \multicolumn{3}{|l|}{ Age at first sexual debut } \\
\hline No sex & & $0.00^{* * *}$ \\
\hline$\leq 15$ years & & $2.03^{\star * *}$ \\
\hline $16-19$ years & & $1.60^{* * *}$ \\
\hline$\geq 20$ years & & 1.00 \\
\hline \multicolumn{3}{|l|}{ Had an ex-nuptial birth } \\
\hline Yes & & $0.50^{\star \star *}$ \\
\hline No & & 1.00 \\
\hline \multicolumn{3}{|l|}{ Childhood place residence } \\
\hline Urban & & 1.00 \\
\hline Rural & & 0.93 \\
\hline \multicolumn{3}{|l|}{ Type of place of residence } \\
\hline Urban & & 1.00 \\
\hline Rural & & $1.13^{*}$ \\
\hline \multicolumn{3}{|l|}{ Region of residence } \\
\hline Nairobi & & 1.00 \\
\hline Central & & 0.94 \\
\hline Coast & & $1.49^{* * *}$ \\
\hline Eastern & & 0.98 \\
\hline Nyanza & & $1.39^{* \star *}$ \\
\hline Rift Valley & & $1.16^{*}$ \\
\hline Western & & $1.32^{* \star *}$ \\
\hline \multicolumn{3}{|l|}{ Religion } \\
\hline Catholic & & 1.10 \\
\hline Protestant \& other Christian & & 1.09 \\
\hline Other religions & & 1.00 \\
\hline \multicolumn{3}{|l|}{ Year of birth } \\
\hline 1969-1978 & & 1.00 \\
\hline $1959-1968$ & & $1.73^{\star \star *}$ \\
\hline $1948-1958$ & & $1.77^{* \star \star}$ \\
\hline -2Log Likelihood & 93974.66 & 93974.66 \\
\hline Chi-square Change & 666.13 & 5119.89 \\
\hline Degrees of freedom (df) & 2 & 18 \\
\hline Sample & 7881 & 7881 \\
\hline Censored & 2375 & 2375 \\
\hline
\end{tabular}

Notes: Significance: ${ }^{* \star} p<0.000,{ }^{* *} p<0.01,{ }^{*} p<0.05$.

Source: Primary Analysis of the 1998 KDHS data 
Table 3: Hazard models of the risk of first marriage by age, Kenya: 1998 KDHS

\begin{tabular}{|c|c|c|c|c|c|c|}
\hline \multirow{3}{*}{ Covariates } & \multicolumn{6}{|c|}{ Age at survey in years } \\
\hline & \multicolumn{2}{|l|}{$15-29$} & \multicolumn{2}{|l|}{$30-39$} & \multicolumn{2}{|l|}{$40-49$} \\
\hline & Model 1 & Model 2 & Model 1 & Model 2 & Model 1 & Model 2 \\
\hline \multicolumn{7}{|l|}{ Level of education } \\
\hline None & 1.00 & 1.00 & 1.00 & 1.00 & 1.00 & 1.00 \\
\hline Primary & $0.39^{* * *}$ & $0.50^{* \star *}$ & $0.81^{* *}$ & $0.83^{\star *}$ & $0.82^{* *}$ & 0.91 \\
\hline At least secondary & $0.28^{* * *}$ & $0.34^{* * *}$ & $0.51^{* * *}$ & $0.60^{\star * *}$ & $0.50^{* * *}$ & $0.71^{* *}$ \\
\hline \multicolumn{7}{|l|}{ Age at first sexual debut } \\
\hline No sex & & $0.00^{* * *}$ & & $0.00^{* \star *}$ & & na \\
\hline$\leq 15$ years & & $1.47^{* \star *}$ & & $2.46^{* \star *}$ & & $3.02^{* \star \star}$ \\
\hline $16-19$ years & & $1.37^{\star \star \star}$ & & $1.69^{* \star *}$ & & $1.92^{* * *}$ \\
\hline$\geq 20$ years & & 1.00 & & 1.00 & & 1.00 \\
\hline \multicolumn{7}{|l|}{ Had an ex-nuptial birth } \\
\hline Yes & & $0.41^{* * *}$ & & $0.54^{\star \star \star}$ & & $0.57^{* * *}$ \\
\hline No & & 1.00 & & 1.00 & & 1.00 \\
\hline \multicolumn{7}{|l|}{ Childhood residence } \\
\hline Urban & & 1.00 & & 1.00 & & 1.00 \\
\hline Rural & & $1.12^{*}$ & & 0.88 & & $1.15^{*}$ \\
\hline \multicolumn{7}{|l|}{ Usual place of residence } \\
\hline Urban & & 1.00 & & 1.00 & & 1.00 \\
\hline Rural & & 0.90 & & $1.34^{* *}$ & & 1.01 \\
\hline \multicolumn{7}{|l|}{ Region of residence } \\
\hline Nairobi & & 1.00 & & 1.00 & & 1.00 \\
\hline Central & & 1.02 & & $0.70^{*}$ & & $1.20^{*}$ \\
\hline Coast & & $1.61^{* \star \star}$ & & 1.08 & & $2.24^{* \star *}$ \\
\hline Eastern & & 1.03 & & $0.81^{*}$ & & $1.26^{* *}$ \\
\hline Nyanza & & $1.42^{\star \star *}$ & & $1.22^{*}$ & & $2.19^{* \star *}$ \\
\hline Rift Valley & & $1.28^{* *}$ & & 0.89 & & $1.58^{* *}$ \\
\hline Western & & $1.32^{* *}$ & & 1.05 & & $2.19^{\star \star \star}$ \\
\hline \multicolumn{7}{|l|}{ Religion } \\
\hline Catholic & & $1.80^{* * *}$ & & $0.80^{*}$ & & 0.92 \\
\hline Protest./other Christian & & $1.81^{\star \star \star}$ & & $0.81^{*}$ & & 0.96 \\
\hline Other & & 1.00 & & 1.00 & & 1.00 \\
\hline -2Log Likelihood & 40622.28 & 40622.69 & 25627.63 & 25627.63 & 14229.99 & 14229.99 \\
\hline Chi-square change & 201.28 & 2951.84 & 117.66 & 496.23 & 61.66 & 285.85 \\
\hline Degrees of freedom (df) & 2 & 16 & 2 & 16 & 2 & 15 \\
\hline Sample & 4738 & 4738 & 1976 & 1976 & 1167 & 1167 \\
\hline Censored & 2252 & 2252 & 98 & 98 & 25 & 25 \\
\hline
\end{tabular}

Notes: Significance: ${ }^{\star * *} p<0.000,{ }^{* \star} p<0.01,{ }^{*} p<0.05$. na stands for not applicable. Source: Primary Analysis of the $1998 \mathrm{KDHS}$ data. 
women aged 15-29 and those age 30-39 years that the risk of first marriage is higher than that for the women in Nairobi province. In general, the results indicate that the effect of region of residence appears to be stronger among women in aged 40-49 years and those 15-29 olds than those aged 30-39 years.

Religion is also closely associated with the risk of first marriage only among women in the younger cohorts. Among the women aged 15-29, Catholic and Protestant women have higher risks of first marriage than women belonging to other religions. However, among women aged 30-39 years the catholic and Protestant women have lower risks of first marriage compared to women belonging to other religions.

\subsection{Multivariate analysis based on ever- married women}

Table 4 presents results of multiple linear regression analysis involving all the 5506 ever-married women covered during the survey. Model 1 shows the results obtained when education was the only explanatory variable while Model 2 includes the other explanatory variables as well. Table 5 presents the results of the analysis on each of the three cohorts of women. These results clearly show that the education has a significant positive effect on a woman's age at first marriage. The results imply that primary education postpones marriage by about one year while at least secondary postpones a woman age at first marriage by 2.4 years (Model 2 of Table 4). The effects of education are greater for younger cohorts of women than the older cohorts (Table 5).

Similarly, age at first sexual debut has a significant positive effect on a woman's age at first marriage. Its effect is greater for older cohorts of women than for younger cohort (Table 5). Premarital childbearing has a significant effect on age at first marriage. Having an ex-nuptial birth is associated with a delayed entry into first marriage. The effect is greater for older cohorts of women than for younger cohort (Table 5).

Childhood place of residence has no significant on age at first marriage when all ever-married women are considered. However, it has a significant effect among only among women aged 30-39 years (Table 5). Among these women, rural childhood residence was associated with early marriage. Type of place of usual residence has a significant effect on age first marriage when all ever-married women considered and also among women aged 30-39 years. Among these women, rural residence was associated with early marriage.

The other explanatory variables indicated in Table 4 have each significant effect on age at first marriage and their respective effects vary across the three cohorts of women as evident in Table 5. 
Table 4: $\quad$ Linear regression coefficients indicating effects of explanatory variables on age at first marriage (pooled sample of ever married women): Kenya, 1998 KDHS

\begin{tabular}{|c|c|c|}
\hline Explanatory variables & Model 1 & Model 2 \\
\hline A constant & $16.85^{* * *}$ & $15.96^{* * *}$ \\
\hline \multicolumn{3}{|l|}{ Level of education } \\
\hline \multicolumn{3}{|l|}{ None (RC) } \\
\hline Primary & 1.08 & $0.84^{\star * *}$ \\
\hline At least secondary & $3.70^{\star * *}$ & $2.37^{\star * *}$ \\
\hline \multicolumn{3}{|l|}{ Age at first sexual debut } \\
\hline \multicolumn{3}{|l|}{$\leq 15$ years $(R C)$} \\
\hline $16-19$ years & & $1.62^{\star * *}$ \\
\hline$\geq 20$ years & & $4.90^{\star * *}$ \\
\hline \multicolumn{3}{|l|}{ Had an ex-nuptial birth } \\
\hline Yes & & $0.31^{\star \star \star}$ \\
\hline \multicolumn{3}{|l|}{ No $(\mathrm{RC}))$} \\
\hline \multicolumn{3}{|l|}{ Childhood place residence } \\
\hline \multicolumn{3}{|l|}{ Urban (RC) } \\
\hline Rural & & 0.20 \\
\hline \multicolumn{3}{|l|}{ Type of place of residence } \\
\hline \multicolumn{3}{|l|}{ Urban (RC) } \\
\hline Rural & & $-0.29^{\star}$ \\
\hline \multicolumn{3}{|l|}{ Region of residence } \\
\hline \multicolumn{3}{|l|}{ Nairobi (RC) } \\
\hline Central & & $0.63^{*}$ \\
\hline Coast & & $-1.28^{* * *}$ \\
\hline Eastern & & 0.21 \\
\hline Nyanza & & $-1.01^{* * *}$ \\
\hline Rift Valley & & $-0.74^{* * *}$ \\
\hline Western & & $-0.92^{* *}$ \\
\hline \multicolumn{3}{|l|}{ Religion } \\
\hline Catholic & & $0.35^{\star}$ \\
\hline Protestant \& other Christian & & $0.49^{* *}$ \\
\hline \multicolumn{3}{|l|}{ Other religions $(\mathrm{RC})$} \\
\hline \multicolumn{3}{|l|}{ Year of birth } \\
\hline \multicolumn{3}{|l|}{$1969-1978(\mathrm{RC})$} \\
\hline $1959-1968$ & & $0.39^{*}$ \\
\hline $1948-1958$ & & $0.37^{\star *}$ \\
\hline Total sums of squares & 814551.45 & 814551.45 \\
\hline Regression & 9245.05 & 22361.80 \\
\hline Residue & 72206.40 & 59089.65 \\
\hline Degrees of freedom (df) & 2 & 17 \\
\hline Sample & 5506 & 5506 \\
\hline $\mathrm{R}^{2}$ & $11.4 \%$ & $27.5 \%$ \\
\hline
\end{tabular}

Notes: Significance: ${ }^{* \star} p<0.000,{ }^{\star *} p<0.01,{ }^{*} p<0.05$. RC stands for the reference category.

Source: Primary Analysis of the 1998 KDHS data 
Ikamari: The effect of education on the timing of marriage in Kenya

Table 5: $\quad$ Linear regression coefficients indicating effects of explanatory variables on age at first marriage (age cohorts of ever married women): Kenya, 1998 KDHS

\begin{tabular}{|c|c|c|c|c|c|c|}
\hline \multirow{3}{*}{ Explanatory variables } & \multicolumn{6}{|c|}{ Age at survey in years } \\
\hline & \multicolumn{2}{|l|}{$15-29$} & \multicolumn{2}{|l|}{$30-39$} & \multicolumn{2}{|l|}{$40-49$} \\
\hline & Model 1 & Model 2 & Model 1 & Model 2 & Model 1 & Model 2 \\
\hline A constant & $16.06^{\star \star *}$ & $16.23^{\star * *}$ & $16.87^{* * *}$ & $15.63^{* \star *}$ & $17.19^{\star * \star}$ & $17.28^{\star * *}$ \\
\hline \multicolumn{7}{|l|}{ Level of education } \\
\hline Primary & $1.72^{\star \star \star}$ & $1.31^{* * *}$ & $1.24^{* * *}$ & 0.89 & $0.81^{\star \star \star}$ & 0.28 \\
\hline At least secondary & $4.10^{\star \star \star}$ & $2.83^{\star \star *}$ & 4.01 & $2.52^{\star *}$ & $3.92^{\star \star \star}$ & $1.69^{\star \star \star}$ \\
\hline \multicolumn{7}{|l|}{$\begin{array}{l}\text { Age at first sexual debut } \\
\quad \leq 15 \text { years }(\mathrm{RC})\end{array}$} \\
\hline $16-19$ years & & $1.31^{* * *}$ & & $1.68^{\star \star *}$ & & $2.21^{* * *}$ \\
\hline$\geq 20$ years & & $4.05^{\star \star \star}$ & & $5.04^{\star \star *}$ & & $6.21^{\star \star \star}$ \\
\hline \multicolumn{7}{|l|}{ Had an ex-nuptial birth } \\
\hline Yes & & 0.17 & & $0.31^{*}$ & & $0.77^{*}$ \\
\hline \multicolumn{7}{|l|}{ No $(R C))$} \\
\hline \multicolumn{7}{|l|}{ Childhood residence } \\
\hline \multicolumn{7}{|l|}{ Urban $(R C)$} \\
\hline Rural & & 0.18 & & $-0.55^{*}$ & & -0.28 \\
\hline \multicolumn{7}{|l|}{ Usual place of residence } \\
\hline \multicolumn{7}{|l|}{ Urban (RC) } \\
\hline Rural & & 0.04 & & $-0.70^{*}$ & & 0.03 \\
\hline \multicolumn{7}{|l|}{ Region of residence } \\
\hline \multicolumn{7}{|l|}{ Nairobi (RC) } \\
\hline Central & & 0.26 & & $1.45^{* \star *}$ & & -0.13 \\
\hline Coast & & $-1.41^{* \star *}$ & & -0.43 & & $-2.53^{\star \star *}$ \\
\hline Eastern & & 0.04 & & 0.72 & & -0.48 \\
\hline Nyanza & & $-1.11^{* * *}$ & & -0.33 & & $-2.22^{\star * *}$ \\
\hline Rift Valley & & $-0.93^{* *}$ & & -0.10 & & $-1.59^{\star \star \star}$ \\
\hline Western & & $-0.95^{* *}$ & & -0.12 & & $-2.29^{\star \star \star}$ \\
\hline \multicolumn{7}{|l|}{ Religion } \\
\hline Catholic & & -0.07 & & $0.42^{*}$ & & 0.26 \\
\hline Protestant/other Christian & & 0.04 & & $0.52^{*}$ & & $0.80^{*}$ \\
\hline \multicolumn{7}{|l|}{ Other $(\mathrm{RC})$} \\
\hline Total sums of squares & 24307.25 & 24307.24 & 32605.38 & 32605.38 & 24267.56 & 24267.56 \\
\hline Regression & 3668.26 & 7412.16 & 3949.19 & 8896.35 & 1815.11 & 6549.74 \\
\hline Residue & 20638.99 & 16895.08 & 28658.19 & 23707.03 & 22452.45 & 17717.82 \\
\hline Degrees of freedom (df) & 2 & 15 & 2 & 15 & 2 & 15 \\
\hline Sample & 2486 & 2486 & 1878 & 1878 & 1142 & 1142 \\
\hline$R^{2}$ & $15.1 \%$ & $30.1 \%$ & $12.1 \%$ & $27.3 \%$ & $7.3 \%$ & $26 \%$ \\
\hline
\end{tabular}

Notes: Significance: ${ }^{* \star} p<0.000,{ }^{* \star} p<0.01,{ }^{*} p<0.05$. RC stands for reference category and na stands for not applicable. Source: Primary Analysis of the 1998 KDHS data. 


\section{Discussion}

This paper investigated the effect of education on the timing of marriage among Kenyan women and the relative effects of education across generations of women. The results obtained using the data drawn from the 1998 Kenya Demographic and Health Survey clearly showed that education has a statistically significant and strong delaying effect on marriage. The effect remained robust in the presence of a number of controls. Each additional level of education lowers the probability of first marriage significantly. The risk of first marriage was 24 percent lower for the women with primary education and 46 percent lower at least secondary education, all compared with women with no education. In all the three cohorts of women, educated women are more likely to delay marriage. Significant variations in the effect of education across the generations of women are apparent. The effect is greater for the younger women, indicating increased postponement of marriage. Analysis based on only ever-married women also indicated that education is has significant positive effect on age at first marriage. For example, at least secondary education delayed first marriage for 2.4 years. These results provide empirical evidence that a woman's educational attainment is an important determinant of a women's age at first marriage in Kenya. More education leads to delayed marriage. These results are consistent with those reported earlier in the literature.

Premarital sexual activity has an effect on the timing of marriage. An early of age at first sexual is associated with increased probability of first marriage. Women who initial sexual activity before the age of 20 years are significantly more likely to entry into early marriage than those who start sexual activity when they are at least 20 years old. As expected women who have no sexual experience are less likely to enter into early marriage compared to those who are sexually experienced. The results indicate the effect of age at first sexual debut differs across generations of women; it is stronger for the older cohorts than for young cohorts, indicating a weakening of the association between the onset of sexual activity and early marriage.

Premarital childbearing, as represented by whether or not a woman had an exnuptial child, has a significant effect on age at first marriage. Having an ex-nuptial birth significantly lowers the probability of marrying early. The results show that the risk of first marriage is 50 per cent lower for women with an ex-nuptial birth compared those with an ex-nuptial birth. Whether or not a woman has an ex-nuptial birth is significantly associated with the risk of first marriage among women in all the generations of women examined in this study. The effect is greater for the younger cohorts than the older cohorts than. Having an ex-nuptial birth lowers the risk of marriage by 59 per cent, 46 per cent and 43 per cent for the 15-29, 30-39 and 40-49 cohorts, respectively. Analysis on ever-married women also indicates that having an ex-nuptial birth is positively associated with age at first marriage. Generally, the results reflect the reality about the 
association between premarital childbearing and marriage in Kenya. In most communities in Kenya, it is not culturally and socially acceptable for a young man to marry, as a first wife, a woman who already has a child from another relationship. As result, prospective suitors generally avoid women with ex-nuptial births. In addition, women who have ex-nuptial births tend to distrust men and as such they are rather reluctant to form relationships with men.

As expected women in more developed provinces are less likely to marry early than women in less developed provinces. The results indicate that women in Coast, Nyanza, Western and those in Rift Valley province are significantly more likely to marry early than those in Nairobi province. Compared with the women in Nairobi province, the risk of first marriage was not statistically different for women in Central, Eastern and Rift Valley province. The results indicate that effect of region of residence is strong across the generations of women but appears to be stronger for the older cohorts. The results indicate that Catholic and Protestant women are more likely to marry later compared to women belonging to other religions. The effect of religion appears to be consistent across generations of women.

Both the place of childhood residence and usual place of residence are weakly associated with the timing of first marriage and their relative effects vary across the three cohorts of women. Childhood place of residence has a significant effect only for women in the 15-29 and 40-49 - age cohorts. In these two cohorts women who grew up in rural areas had a slightly higher risk of first marriage compared to those who grew up in urban areas. Usual place of residence had a significant effect only for the 30-39-age cohort. In this cohort, rural women had a higher risk of first marriage compared to urban women. Finally, the results indicate younger women are less likely to early marry compared older women, indicating a downtrend in the occurrence of early marriage in the country.

All in all, the study has established that a woman's educational attainment, premarital sexual activity, premarital childbearing, type of place of residence, region of residence, religion and year of birth are each important in determining the woman's age at first marriage in Kenya.

This study has implications for policies and programs that seek to increase women's age at first marriage. It is crucial to continue improving girls and young women access to education in the country, as this is important avenue for raising the women's age at first marriage and for empowering women and enhancing their participation in market economy. Similarly, it is advisable to target young women, particularly those with no or little education, with information on reproductive health and to provide them with basic life skills to enable them to avoid early sexual activity and ultimately early marriage. These should include primary school girls. This should be done throughout the country with more emphasis placed on the least developed parts 
of the country such as those in Western, Coast, Nyanza and the less developed parts of the Rift Valley province. These programs should emphasis the health as well as the economic advantages of delayed marriage and childbearing.

The pathways through which education influenced the timing of marriage were not investigated in this study due to lack of data. Similarly, interactions between and among the covariates included in this study were not investigated. Future studies on this subject should endeavour to seek for the pathways and investigate interactions between and among covariates.

\section{Acknowledgements}

The author would like to thank Andrew Mutuku, Rose Towett and the anonymous reviewers for useful comments and suggestions on the earlier version of this article. 


\section{References}

Addai, Isaac and Frank Trovato. (1999). "Structural assimilation and ethnic fertility in Ghana". Journal of Comparative Family Studies 30(3):409-427.

Allison, Paul. (1984). Event History Analysis: Regression for Longitudinal Data. Sage.

Allison, Paul D. (1995). Survival Analysis Using the SAS System: A Practical Guide, Cary,North Carolina: SAS Institute Inc.

Amin, Sajeda. (1995). Female education and fertility in Bangladesh: The Influence of marriage and the family. In Girl's Schooling, Women's Autonomy and Fertility Change in South Asia, eds. Roger Jeffery and Alaka Basu. Sage Publications, New Delhi, London and Newbury Park.

Arnaldo, Carlos. (2004). "Ethnicity and Marriage Patterns in Mozambique". African Population Studies vol. 19(1): 143-164.

Bennett, Neil G., David E. Bloom and Cynthia K. Miller. 1995. The Influence of Nonmarital Childbearing on the Formation of First Marriages. Demography 32(1): 47-62

Bloom, D. E., and Trussell, J. (1984). "What are the determinants of delayed childbearing and permanent childlessness in the United States?", Demography, 21, 591-611.

Blossfeld, H. P. and J. Huinink. (1991). Human Capital Investments or Norms of RoleTransition? How Women's Schooling and Career Affect the Process of FamilyFormation. American Journal of Sociology 97(1): 143-168.

Blossfeld, H.P., and Jaenichen, U. (1992)."Educational expansion and changes in women's entry into marriage and motherhood in the Federal Republic of Germany". Journal of Marriage and the Family, 54, 302-315.

Bracher, Michael and Gigi Santow. (1998). "Economic independence and union formation in Sweden". Population Studies 52(3):275-294

Caldwell, J. C. and Pat Caldwell, (1987). "The Cultural context of high fertility in SubSaharan Africa'. Population and Development Review, 13(3): 409-437.

Caldwell, J.C., P.H. Reddy, and P. Caldwell. (1983). "The causes of marriage change in South India," Population Studies 37(3): 343-361.

Coale, A.J. (1973). "The demographic transition". IUSSP International Population Conference Proceedings, Vol. I., Liège, pp. 53-71. 
Chiswick, C. and E. Lehrer. (1990). "On marriage-specific human capital: Its role as a determinant of remarriage." Journal of Population Economics 3:193-213

Choe, Minja K., Shyma Thapa and Vinod Mistra, (2004). 'Early marriage and early motherhood in Nepal". Journal of Biosocial Sciences (First published on line 2004) 00: 1-20.

Davis, Kingley and Judith Blake. (1956). "Social Structure and fertility: an analytic framework". Economic Development and Cultural Change (Chicago, Illinois), Vol.4. No. 3 (April), pp: 221-235.

Dixon, R.B. (1971). "Explaining cross-cultural variations in age at marriage and proportions never marrying", Population Studies 25(2): 215-234.

Ewbank, D. C, R. Hennin and J. Kekovole, (1986). "n integration of demographic and epidemiologic research on mortality in Kenya', United Nations , eds. Determinants of Mortality Change and Differentials in Developing Countries, The Five Country Case Study Project”, United Nations, New York: PP: 33-79.

Ezeh, A. C. and F. N. A. Dodoo, (2001). "Institutional Change and African Fertility Transition: the case of Kenya". Genus Vol. LVII no.3-4 Pp.53-73.

Goldscheider, Calvin. (1971). Population, Modernization, and Social Structure. Boston: Little, Brown and Company.

Goldscheider, F. K., and Waite, L. J. (1991). New families, no families? The transformation of the American home. Berkeley: University of California Press.

Goode, William, J. (1963). World Revolution and Family Patterns. New York. Free Press of Glenoe.

Hertrich, Véronique. (2002). "Nuptiality and gender relationships in Africa: An overview of first marriage trends over the past 50 years," session on Family Change in Africa and Latin America, Population Association of America Annual Meeting, Atlanta, 9-11 May.

Jejeebhoy, S.J. (1995). Women's Education, Autonomy, and Reproductive Behavior: Experience from Developing Countries. Oxford: Clarendon Press.

Jensen, Robert and Rebecca Thornton (2003). Early female marriage in the developing world. In Gender, Development and Marriage, Caroline Sweetman, ed. Oxfam GB, Oxford, UK. 
Ikamari, Lawrence D.E. (1996). Factors affecting child survival in Kenya. PhD Thesis. The Demography Program. The Research School of Social Sciences. The Australian National University. Canberra: Australia

Kaufman, G. L. and D. Meekers. (1998). "The impact of women's socioeconomic position on marriage patterns in sub-Saharan Africa". Journal of Comparative Family Studies 29(1):101-114.

Lesthaeghe, Ron, Georgia Kaufmann and Dominique Meekers. (1989). "The Nuptiality regimes in sub- Saharan Africa". In Reproduction and Social Organisation in Sub-Saharan Africa. Ron Lesthaeghe, ed. Berkeley: University Of California Press.

National Council for Population and Development (NCPD),Central Bureau of Statistics, and Macro International Inc. Calverton, Maryland USA. (1999). Kenya Demographic and Health Survey, 1998. Calverton, Maryland: NDPD, CBS, and MI.

Oppenheimer, V. K. (1988). "A theory of marriage timing". American Journal of Sociology, 94, 563-591.

Palmore, James, (1983). The Country Effect: A six nation Overview of the determinants of Nuptiality and Cumulative Fertility. In United Nations: Asian Population Studies Series No.59. Multivariate Analysis of Nuptiality and Fertility for Selected ESCAP Countries. Pp. 6-11.

Quisumbing, Agnes R and Kelly Hallman, (2003). Marriage in transition: Evidence on age, education, and assets from six developing countries'. Policy Research Working paper \# 183. Population Council.

Rindfuss, R. R., and St. John, C. (1983). "Social determinants of age at first birth". Journal of Marriage and the Family, 45, 553-565.

Smith, P.C. (1980). “Asian marriage patterns in transition”. Journal of Family History 5(1): 58-96.

Smith, Peter C. and Karim, Methab. S. (1980). Urbanisation, Education and Marriage Patterns: Four Cases from Asia. East-West Population Centre. Paper \# 70.

Teachman, J. and A. Heckert. 1985. Impact of age and children on remarriage. Journal of Family Issues 6:185-203.

Thornton, A., Axinn, W. G., and Teachman, J. D. (1995). "The influence of school enrollment and accumulation on cohabitation and marriage in early adulthood". American Sociological Review, 60, 762-774. 
UNESCO, (2000). Global Education Database.

United Nations, (1987). Fertility Behaviour in the context of development: Evidence from the World Fertility Survey. Population Studies, no. 100. Sales No. E.86.XIIII.5

United Nations, (1988). First Marriage: Patterns and Determinants: ST/ESA/SER.R/76.

United Nations. (1990). Patterns of First Marriage: Timing and Prevalence. New York: United Nations, Department of International Economic and Social Affairs. ST/ESA/SER.R/111.

Westoff, Charles F. (1992). Age at Marriage, Age at first Birth and Fertility in Africa. World Bank Technical Paper \# 169. Washinton D.C.:The World BanK.

Zabin, L. and K. Kiragu (1998), "The health consequences of adolescent sexual and fertility behavior in sub-Saharan Africa". Studies in Family Planning, 29(2): 210-32. 
Ikamari: The effect of education on the timing of marriage in Kenya 